\title{
DEMOGRAPHIC DETERMINANTS OF CREATIVITY: THE ANALYSIS OF THE DEVELOPMENT OF CREATIVE POTENTIAL AND FORECAST FOR THE BALTIC STATES
}

\author{
Vladimirs ROJENKO ${ }^{1}$, Aleksandrs DAHS ${ }^{2}$ \\ ${ }^{1,2}$ University of Latvia, Latvia \\ Corresponding author e-mail: vladimirs.rojenko@lu.lv
}

\begin{abstract}
Human capital, affected by the demographic determinants, nowadays becomes a novel driver of change and regional development. Changes in the modern economy determine the future leading role of human capital, especially its creative dimension in the development of modern, sustainable competitive advantages of countries and regions. Considering the negative demographical tendencies in the Baltic States, the aim of this paper is to analyse and forecast the development of creative potential in Lithuania, Latvia and Estonia. Our methodology is based on the estimation of a regression model describing the relations between Global Creativity Index (GCI) and its components with the available demographic data in 28 European Union member countries. Model estimation results indicate a particular importance of population age composition for all GCI components, while education attainment levels appear to be highly significant for the technology and talent components. Using the estimated model parameters, authors elaborate a simple forecast for the three Baltic States using the current demographic projections, while outlining the strengths and potential weaknesses of each country in the long-term perspective.
\end{abstract}

Keywords: Creativity, demographic development, global competitiveness, human capital.

\section{INTRODUCTION}

In order to ensure the opportunity of sustainable development and welfare of its citizens the EU is strengthening its global competitiveness by removing barriers to innovation and making it easier for the public and private sectors to work together and cooperate in the field of delivering, implementing and developing innovations. These days, there is a growing consensus that Europe must do more to develop human capital that will determine our future economic prosperity, to create an economy where innovations form a core part of daily economic life of every country and region across the EU (Schleicher, 2006). The EU innovation and economic development policy is based on innovation, human capital and creativity which increase opportunities for individuals and tackle social exclusion (Figel, 2009). Three Baltic States, which have at the same time become part of the EU in 2004, nowadays hold different positions in innovative development. According to the EU Innovation Scoreboard 2015, positions of the Baltic States are still lower than the EU average. Compared with Latvia and Lithuania, which for many years are among the moderate innovators, Estonia is more successful in the field of innovation 
growth (European Commission, 2016). The mentioned tendencies in the field of innovative development and the relatively high position of the Baltic States (16-23 in the overall world ranking) in the human capital index, developed by the World Economic Forum, indicate the existing problems connected with human capital stagnation, underinvestment in education and training, depopulation, aging population and other social and demographic problems (World Economic Forum, 2015). Considering the core role of the creative potential of human capital in the development of new competitive ideas and innovations, it is necessary to identify the links and relationships between human capital, creative potential and demography. Using the mix of the aforementioned factors it is also possible to forecast the future economic landscape. In order to identify possible development strategies of the Baltic States and to predict conditions, that determine future environment, it is necessary to develop clear and permanent paths in the economic and social landscape of the future (Stimson, Stough, \& Roberts, 2006). Considering the information stated above, the aim of this paper is to analyse and forecast the development of human capital creative dimension in Lithuania, Latvia and Estonia for the period until 2050. In order to achieve the aim stated above we have set the following tasks:

1. To analyse the theory and concepts of human capital creative dimension;

2. To analyse the impact of demographic factors on the creative potential of the EU;

3. To forecast the development of creative potential of the Baltic States until 2050.

Our methodology is based on the estimation of a regression model describing the relations between Global Creativity Index (GCI) and its components with the available demographic data in 26 European Union member countries. Model estimation results indicate a particular importance of population age composition for all GCI components, while education attainment levels appear to be highly significant for the component technology. Further, using the estimated model parameters, authors elaborate a simple forecast for the three Baltic States using the current demographic projections, while outlining strengths and potential weaknesses of each country in the long-term perspective. In order to match the time period of the GCI report available at the time of the research, we can only use statistical information for the year 2011 and limit our forecasts with the year 2050. Information sources of our research were a wide range of scientific literature and the statistical data of EUROSTAT and Martin Prosperity Institute (Canada).

Our research presents a brief forecast of the development of creative potential of human capital in the Baltic States, that gives an opportunity to identify the current weaknesses of regional and economic development policies of the EU and of every state determining the future economic and social landscape. This information provides the basis for further research and material for changes in economic and regional development policies of the Baltic States in long-range perspective. 


\section{THEORY AND CONCEPTS}

Nowadays a fundamental transformation from resource-based economy to modern knowledge-based economy is underway all around the world. The economic landscape is rapidly changing, affecting the ways of life, structure of national economies and habits of private and corporate consumption (Florida, 2010). Changes occurring in the external and internal environment of the globalized economics affect the way in which economic developers foster the environment, which encourages growth of existing businesses and promotes the establishment of new forms of business and uncontested market spaces. Ordinary goods and services are no longer sufficient for private and corporate customers, who nowadays are seeking new experiences - memorable events that engage them in an inherently personal ways (Gilmore \& Pine, 2007). The most successful and profitable products presented at all kinds of markets are innovative, unique and highly qualitative goods and services that give customers an opportunity to gain new, previously unknown experiences. Nowadays market leaders are successful only when they are meeting expectations of modern customers and create new and innovative market niches. Therefore, human capital and its creative dimension becomes a new source of sustainable innovative development, resulting in the appearance of unique innovation trends and new, uncontested market spaces that makes competition less relevant and ensures the opportunity of sustainable development in the future (Mauborgne \& Kim, 2005).

According to Florida (2010) the main driver of modern economy is a special group of workers - "Creative Class". They are the people for whom creating and developing new, innovative ideas is a daily routine. Analysing the differences in the development of countries, Florida (2010) has determined that the regions with a higher proportion of "Creative Class" representatives are more successful and able to develop successfully and realize their inherent competitive advantage (Florida, 2010). In order to compare the development of human capital creative dimension in different countries the Global Creativity Index (further - GCI) was developed. The GCI is measured using three core dimensions of creativity - Technology, Tolerance and Talent (Florida, 2010). The technological dimension of GCI includes the share of GDP devoted to R\&D activity and number of the applied patents per capita, the talent dimension includes the share of workforce in the creative class and the share of adults with higher education, in its turn the tolerance dimension includes the share of people who are tolerant to racial minorities, gay and lesbian people (Florida, Mellander, \& King, 2015). All of the GCI dimensions are equally important, and only by combining all of them, the competitive, attractive and creative potential will effectively emerge (Kalsø Hansen, 2007). Florida (2010) and the researchers from Martin Prosperity Institute (a part of the Rotman School of Management at the University of Toronto) point out that there is a strong correlation between a country's creativity and competitiveness, which indicates a significant role of human capital's creative potential in the development of modern competitive economies (Florida, Mellander, \& King, 2015).

Studies on regional development features, conducted by the series of researchers during the last decades, show that human capital development factors, 
and especially - its creative dimension, not only play an important role in spurring regional development, but are also strongly connected with regional development tendencies and are determined by the individual characteristics of the region under study (Lee, Florida, \& Gates, 2010). The overall human capital development opportunities of the specific countries or regions are generally determined by various demographic factors. Most important of them are age distribution of population and education attainment that directly affect human capital and its creative potential development opportunities: human mind productivity and appropriateness for certain creative work and employment. Considering, that stock of human capital also changes with age means that the person will be better suited for different types of employment at different intervals of the lifecycle (Bönte, Falck, \& Heblich, 2007). Traditionally young people are more creative, brave and risk-taking, whereas elder people usually have wide and long-range experience and are able to realize it in new creative ideas. Level of education and training of people in appropriate age categories are seen as the most important investments in human capital (Florida, Mellander, \& Stolarick, 2008).

Summarising the ideas presented above, it is possible to claim that strengthening of the creative dimension of the country or region provides an opportunity to achieve an economical breakthrough and strengthen modern competitive advantages. Smart management of regional development policy and consideration of appropriate demographical factors provide an opportunity to accelerate and/or better control the development of the human capital creative dimension.

\section{METHODS AND PROCEDURES}

Before proceeding with the quantitative analysis of the relations described above, one must understand the possibilities offered and limitations imposed by the available empirical data for the indicators and processes under study. It is critically important to find, evaluate and retrieve the most relevant quantitative information for the particular geographical scope and time period of the study.

In our case, two major data sources should be addressed. The first source is the accumulation of empirical research in the form of individual papers, reports and data tables concerning the GCI and its three main components. In this particular study, we rely mainly on the data presented in the report "The Global Creativity Index" of year 2015 developed by the Martin Prosperity Institute (Florida, Mellander, \& King, 2015). Although, the report is somewhat outdated, it remains to be the most complete and relevant accumulation of the GCI data. The report includes the rankings of 139 world countries by each of the three CGI components and provides the resulting GCI scores for each evaluated country.

The second source is the statistical information on relevant demographic indicators, as well as reliable population forecasts. For the purpose of this study, we use the Eurostat (EUROSTAT, 2015) tables on population age distribution, education attainment levels and population age distribution forecasts for the three Baltic States. In order to match the time period of the GCI report, we can only use 
statistical information for the year 2015. We also limit our forecasts to the year 2050 .

Our research methodology is based on the sequential estimation of the linear regression model. At first we estimate the model for the GCI itself:

$$
G C I_{i}=\alpha+\beta_{j} X_{i j}+\beta_{k} Z_{i k}+\beta_{c} C_{i}+\varepsilon
$$

where $\boldsymbol{X}_{i j}$ is a share of population in the specific age group $j$ (groups of under $15,15-24,25-34,34-44,45-54,55-64$ and 65-75 years respectively) in country $i, Z_{i k}$ stands for the rate of education attainment to the level $k$, (secondary education, and tertiary education respectively, in accordance with the ISCED 2011 system (UNESCO, 2012)) in country $i$ within the population aged between 15 and $64 . C_{i}$ represents the total rate of population change in country $i$. $\boldsymbol{\beta}_{j}$ and $\boldsymbol{\beta}_{\boldsymbol{k}}$ denote the estimated regression parameters for the age group $j$ and education attainment level $k$. Parameter $\boldsymbol{\beta}_{\boldsymbol{c}}$ stands for the regression coefficient of the total rate of population change $C$.

Then we proceed with the follow-up estimations for the global rank of each GCI component (Talent, Tolerance and Technology) in each particular country:

$$
T_{l i}=\alpha+\beta_{j} X_{i j}+\beta_{k} Z_{i k}+\beta_{c} C_{i}+\varepsilon
$$

where $\boldsymbol{T}_{l i}$ is the respective GCI component's rank 1 of country $i$. Other parameters and abbreviations remain the same for these sub-models.

\section{RESULTS}

Table 1 shows the main estimation results for the models described in previous sections. Standard deviations of the coefficients are given in brackets.

Table 1. Linear Model Estimation Results of the Impact of Selected Demographic Factors on the GCI and its Component Global Ranks in 28 EU countries in 2015

\begin{tabular}{|c|c|c|c|c|}
\hline Parameter & $G C I$ & Talent rank & $\begin{array}{l}\text { Technology } \\
\text { rank }\end{array}$ & $\begin{array}{l}\text { Tolerance } \\
\text { rank }\end{array}$ \\
\hline Population aged under $15(\%)$ & $5.491 *$ & -3.476 & 0.915 & $-17.932 * * *$ \\
\hline Population aged 15-24 (\%) & $-1.148^{6}$ & 0.001 & $8.373 * *$ & -5.506 \\
\hline Population aged 25-34 (\%) & $-5.158^{6}$ & 2.761 & 17.751 & -4.630 \\
\hline Population aged 35-44 (\%) & 1.784 & -1.593 & 1.337 & -7.069 \\
\hline Population aged 45-54 (\%) & $4.312^{6}$ & -3.792 ' & 6.019 & $-19.834 *$ \\
\hline Population aged 55-64 (\%) & $7.324 *$ & $-8.254 *$ & -1.771 & $-17.308^{6}$ \\
\hline Population aged 65-74 (\%) & 4.465 & -5.223 & 6.779 & -19.462 ' \\
\hline Crude population change (\%) & $0.010 * *$ & 0.056 & $-2.369 * * *$ & $-1.352^{6}$ \\
\hline Secondary education att. (\%) & 0.000 & -0.219 & $-0.733 *$ & $1.391 * *$ \\
\hline Tertiary education att. (\%) & $0.010 * *$ & $-1.966 * * *$ & $-1.420 * *$ & 0.224 \\
\hline$R^{2}$ & 0.866 & 0.729 & 0.876 & 0.779 \\
\hline $\mathbf{F}$ & 10.955 & 0.569 & 0.804 & 0.649 \\
\hline
\end{tabular}

(authors' calculations based on the Eurostat data)

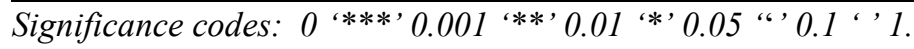


Before interpreting the model estimation results it is important to note, that, while GCI itself is and index limited by values between 0 and 1 (where 1 is the best possible result), its component rankings represent the actual rank of the country on the global scale; and therefore - the lower rank number (i.e. 1 out of 100) stands for the best result.

Parameters $R^{2}$ and $\mathrm{F}$ included in the table are the traditional indicators for the overall quality-of-fit for each particular model, and have been extensively explained in the specialised literature (Seber \& Lee, 2012).

Model estimations clearly demonstrate that the EU countries with higher shares of population in "15-24" and "25-34" age groups significantly lag in terms of the GCI. Countries with relatively higher share of population in "15-24" group face significant challenges in terms of Technology, with $1 \%$ increase in this population group, in average, leading to loss of 8 positions in global ranking), while "24-34" age group shows notable (although statistically insignificant) impact on both Talent and Technology.

Presence of the high share of population under 15 years of age in the country shows strong positive impact on GCI through highly significant influence on the Tolerance rank. Cohorts of "45-54" and "55-64" appear to boost the country's GCI, through moderately significant but numerically high impact on Talent and Tolerance components. Observing model estimation results for the Tolerance ranking, it is possible to theorise the existence of distinct dichotomy between the two major age groups of population: " $15-44$ " cohort has a mixed and mostly negative effect on this rank, while the population above 45 years of age is contributing significantly to the improvement of Tolerance in the country.

Countries with higher "Crude population change" rate tend to have higher GCI, as growing populations seem to facilitate a much higher Technology rank and the above average Tolerance.

Lack of any clear indication of positive effects of the remaining " $35-44$ " age group may be partially explained by the complex sub-division of this group by education, qualification, social status and other characteristics, leading to the future formation of the "Creative Class" group when this cohort progresses in time reaching the highly effective age of 45-64, as suggested by Florida (2010) and confirmed by our model estimations.

The picture is quite clear with the education attainment parameters, with tertiary education attainment level being positively significant for the GCI in general and its Technology and Talent components: $1 \%$ increase in tertiary education attainment, in average, resulting in the 0.01 increase of GCI and bringing a country two steps higher in the global Technology and one step higher in the global Talent ranking. Secondary education attainment appears to have only moderate positive effect on Technology, while significantly degrading the country's Tolerance position.

From the limited information produced by this exploratory study, we can make a provisional conclusion that at the time period of the study, in the EU member states, residents in the age group of 45-64 with the completed tertiary education were the most likely representatives of the much speculated "Creative Class". 


\section{FORECAST}

Using the model estimation results (particularly - the $\beta$ coefficients of the various age groups and the "Population change rate") and relying upon the available population forecasts produced by Eurostat (main scenario) it is now possible to make a crude forecast predicting the change in creative potential of the selected countries resulting from the change in population age structure over the years. In order to produce such a forecast one needs to use the model (1) in form of a complete equation, with the GCI index value or the respective rank of the country playing the role of an unknown variable. Then, by multiplying the estimated values of the relevant $\beta$ values by the forecasted values of the respective model variables $(X, Z$ and $C$ ) on the right hand side of the equation, it is possible to produce the desired predicted value of the dependant variable.

We obtain the forecasted share of population in the specific age group $(X)$ values and Crude population change rate $(C)$ for year 2030 and 2050 from the Eurostat EU population forecast tables (EUROSTAT, 2015). Keeping in mind the limitations of this study, we assume no change in the education attainment levels.

In this paper we have chosen to focus our forecast on the Three Baltic States Estonia, Latvia and Lithuania, which share a rather unique population age and gender structure (see Fig. 1). Unlike the majority of the 28 EU member states, Estonia, Latvia and Lithuania have experienced a noteworthy but temporary increase in birth rate during the late 1980s and early 1990s, which is often referred to as the late Soviet "baby-boom" (Lutz, Scherbov, \& Volkov, 2002). This period of high birth-rate was followed by the rapid decrease in fertility causing speculations over the long-term perspectives and sustainability of the human capital in these countries.

Figure 1 shows the current age-gender structures of the three Baltic States in comparison with the total EU28 population, highlighting the late 1980's and early 1990's "baby-boom" cohort in the Baltic States.
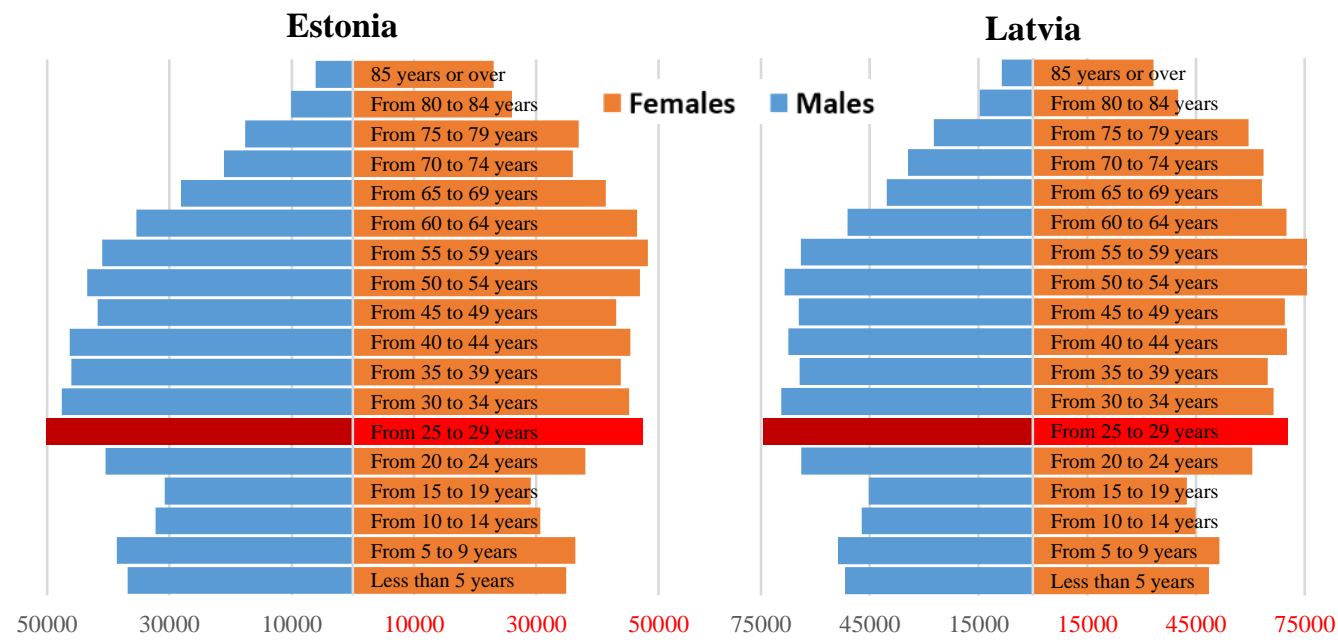

Fig. 1. Population pyramids of Estonia and Latvia as of 1 January 2015 (authors' elaboration based on Eurostat data). 


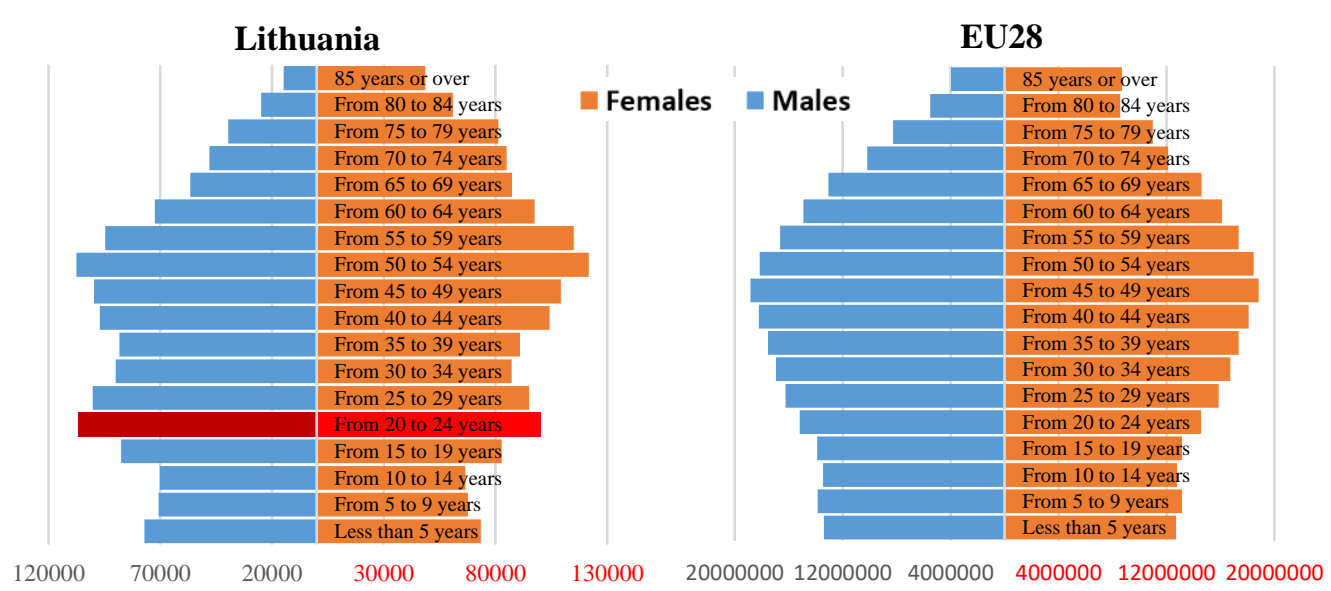

Fig. 2. Population pyramids of Lithuania and EU28 as of 1 January 2015 (authors' elaboration based on Eurostat data).

Considering the information presented in these graphs, it is interesting to observe the change in the forecasted indicators, as the wider population cohorts identified in Fig. 1 reach the age of different modelled age groups in 2030 and 2050 respectably.

Table 2 presents the projections of the GCI levels and the change in global rankings of the GCI components for three Baltic countries in years 2030 and 2050.

Table 2. Forecast of the GCI and its Component Rankings of the Baltic States, Main Scenario in 2030 and 2050 (authors' elaboration based on the Eurostat data)

\begin{tabular}{c|c|c|c|c|c}
\hline \hline Country & Year & GCI & Talent rank & $\begin{array}{c}\text { Technology } \\
\text { rank }\end{array}$ & $\begin{array}{c}\text { Tolerance } \\
\text { rank }\end{array}$ \\
\hline \multirow{4}{*}{ Estonia } & 2015 & 0.625 & 16 & 33 & 87 \\
& $\mathbf{2 0 3 0}$ & $\mathbf{0 . 9 4 6}$ & $\uparrow \mathbf{2 2}(-6)^{1}$ & $\uparrow \mathbf{5 0}(-17)$ & $\uparrow \mathbf{2 7}(60)$ \\
& $\mathbf{2 0 5 0}$ & $\mathbf{0 . 7 2 7}$ & $\downarrow \mathbf{1 5}(21)$ & $\uparrow \mathbf{9}(-26)$ & $\downarrow \mathbf{7 3}(133)$ \\
\hline \multirow{4}{*}{ Latvia } & 2015 & 0.563 & 22 & 54 & 77 \\
\cline { 2 - 7 } & $\mathbf{2 0 3 0}$ & $\mathbf{0 . 9 1 4}$ & $\uparrow \mathbf{2 9}(-7)$ & $\uparrow \mathbf{5 9}(-5)$ & $\uparrow \mathbf{1 5}(62)$ \\
& $\mathbf{2 0 5 0}$ & $\mathbf{0 . 5 1 2}$ & $\downarrow \mathbf{4 4}(37)$ & $\mathbf{0}(-5)$ & $\downarrow \mathbf{1 0 5}(167)$ \\
\hline \multirow{4}{*}{ Lithuania } & 2015 & 0.490 & 12 & 65 & 105 \\
& $\mathbf{2 0 3 0}$ & $\mathbf{0 . 9 4 9}$ & $\uparrow \mathbf{3 6}(-22)$ & $\uparrow \mathbf{6 7}(-2)$ & $\uparrow \mathbf{4 2}(63)$ \\
& $\mathbf{2 0 5 0}$ & $\mathbf{0 . 3 2 0}$ & $\downarrow \mathbf{7 5}(53)$ & $\downarrow \mathbf{4}(2)$ & $\downarrow \mathbf{1 5 3}(216)$ \\
\hline
\end{tabular}

Notes: ${ }^{1}$ relative rank change in comparison with the previous forecast year (actual predicted rank is shown in brackets)

When analysing the predictions made in Table 2, it is crucial to remember, that the presented scenario is only valid for the three Baltic countries under the conditions that all other countries participating in the ranking remain at their 2015 levels without change. Therefore, these results should only be addressed as an 
analytical tool showing the potential dynamics of the GCI and its components under the influence of the future population change.

Our projections indicate that in terms of GCI and its components, by 2030, all three countries are going to benefit from the cohort of "baby-boomers" (highlighted in Fig. 1) reaching the "Creative Class" age group of "45-64". By 2050, however, as the same cohort will move on into the "over 65" age group, the significant reduction in the creative potential is to be expected, with Talent remaining as the only high ranking component in all three countries. Latvia and Lithuania face the risk of returning to the 2015 levels of GCI, while Estonia might retain a relatively higher creativity level.

As it was stated above, the main reason of the negative GCI development scenario is strongly connected with negative demographic development trends in all Baltic States. According to Eurostat projections, the total number of population in the Baltic States will dramatically decrease in next decades. The Eurostat forecast predicts at least $34 \%$ total population loss for Lithuania, $27 \%$ for Latvia and $14 \%$ for Estonia till year 2050 (EUROSTAT, 2015). Differences in GCI development trends arise from the essential differences of socio-economic landscapes and particular national characteristics of the Baltic States. Estonia, as an undisputed GCI leader in 2015, through the active innovation, education and research development policy shows the best results in Technology index ranking, which together with relatively favourable demographic development forecast determines its leading role in 2050. The forecast of GCI level change in Latvia indicates the risk of returning to the level of 2015 in the next decades and determines the development of education, innovation and all types of tolerance as the main factor that affects GCI in the time period till year 2050. According to authors' forecast, Lithuania is the most vulnerable of the three Baltic States. High population loss in the next decades and related negative changes in Talent, Technology and Tolerance indexes will affect all areas of economic, political and public life in Lithuania.

Overall GCI development tendencies are very similar in all Baltic States, but it is necessary to take in account that the creative potential of Latvia and Lithuania will be at serious risk during the next decades.

\section{CONCLUSION}

Creativity nowadays becomes a modern source of sustainable competitive advantages, economic welfare and success for the nations, states and regions. Our research has examined the role of the demographic parameters of education attainment and population age structure in the development of the GCI components - Talent, Tolerance, and Creativity as proposed by Florida (2010). We have used a regression model to estimate and describe relations between the GCI and its components with the available demographic data in the EU, then, using the obtained data estimated model parameters we have elaborated a simple GCI and its components for the development forecast for the three Baltic States.

The estimation of the developed regression model allows assuming, that affecting of the demographic development of the country or region may indirectly change various aspects of its creative potential and global competitiveness, which 
is crucial for the long-term economic and regional development planning. Obtained results demonstrate, that the EU countries with higher share of population in "15-24" and "25-34" age groups significantly lag in terms of the GCI. Countries with relatively higher share of population in "15-24" group face significant challenges in terms of Technology ( $1 \%$ increase in this population group is leading to loss of 8 positions in global ranking), while "24-34" age group shows notable impact on both Talent and Technology. In turn, high share of population under 15 years of age in the country shows strong positive impact on GCI through highly significant influence on the Tolerance rank. Cohorts of 45-54 and 55-64 appear to boost the country's GCI through the impact on Talent and Tolerance components. Tertiary and secondary education attainment level is positively significant for the GCI and its Technology and Talent components (1\% increase in tertiary education attainment results in the 0.01 increase of GCI and bringing a country two steps higher in the global Technology and one step higher in the global Talent ranking).

The forecast of GCI and the development of its components for the three Baltic States shows, that by 2030, all three countries are going to benefit from the cohort of "baby-boomers" (born in late 1980s and 1990s) reaching the "Creative Class" age group of " $45-64$ ". However, by the year 2050 when the same cohort will move on into the "over 65" age group, the significant reduction in the creative potential is to be expected with Talent remaining as the only high ranking component in all three countries.

Until the year 2050 Latvia and Lithuania will face serious risk of returning to the 2015 levels of GCI, while Estonia might retain a higher creativity level owing to its higher Technology rank, all of the Baltic States will have an extremely low level of Tolerance by that time. Currently Estonia operates much more effectively in the field of R\&D expenditures, innovation policy, patent application, etc. (European Commission, 2016) and lays the groundwork for long-term development and economic growth (Government Office of the Republic of Estonia, 2014).

Considering the emerging population trends and our estimation results, it is safe to conclude that a comprehensive and pre-emptive policy measures need to be implemented at both the EU and national levels in order to avoid the expected downturn in the competitiveness of the Baltic States and the EU as a whole.

\section{ACKNOWLEDGMENT}

The study was supported by the National Research Program 5.2. EKOSOC-LV: Project 5.2.4. Renewal of society through reducing the risk of depopulation through demographic development and strengthening links with the diaspora for the transformation of the Latvian economy.

\section{REFERENCES}

Bönte, W., Falck, O., \& Heblich, S. (2007). Demography and innovative entrepreneurship. Munich: CESifo working paper, No. 2115. Retrieved from https://ideas.repec.org/p/ces/ceswps/_2115.html

EUROSTAT (2015). Eurostat Population and social condition statistics [Data file]. Retrieved from $\mathrm{http}: / /$ ec.europa.eu/eurostat/data/database 
European Commission. (2016). European Innovation Scoreboard 2016 [Main report file]. https://doi.org/10.2873/48082

Figel, J. (2009) Knowledge: The Foundation for a Stronger Europe. In Arvanitopoulos, C. (Ed.), Reforming Europe: The Role of the Centre-Right (pp. 37-53). Berlin-Heidelberg: SpringerVerlag GmbH. https://doi.org/10.1007/978-3-642-00560-2 4

Florida, R. (2010). The Great Reset: how the new ways of living and working drive post-crash prosperity. New York: HarperCollins Publishing.

Florida, R., Mellander, C., \& Stolarick, K. (2008). Inside the black box of regional development human capital, the creative class and tolerance. Journal of Economic Geography, 8, 615-649. https://doi.org/10.1093/jeg/lbn023

Florida, R., Mellander, C., \& King, K. (2015). Creativity and Prosperity: The Global Creativity Index Report. Retrieved from http://martinprosperity.org/media/Global-Creativity-Index2015.pdf

Gilmore, J. H., \& Pine II, J. B. (2007). Authenticity: contending with the new customer sensibility. Boston, MA: Harward Business School Press.

Government Office of the Republic of Estonia. (2014). Estonian Research and Development and Innovation Strategy 2014-2020 "Knowledge-based Estonia". Retrieved from https://www.hm.ee/sites/default/files/estonian_rdi_strategy_2014-2020_en.doc

Kalsø Hansen H. (2007). Technology, Talent and Tolerance - The Geography of the Creative Class in Sweden. Lund: RAPPORTER OCH NOTISER, Vol. 169. Retrieved from https://lup.lub.lu.se/search/publication/ef61b74e-e9b4-40a9-955c-690aa7af61e6

Mauborgne, R., \& Kim Chan, W. (2005). Blue Ocean Strategy: How to Create Uncontested Market Space and Make Competition Irrelevant. Boston, MA: Harvard Business School Publishing.

Schleicher, A. (2006). The Economics of Knowledge: Why Education is Key to Europe's Success. Lisbon: Lisbon Council Policy Brief, 2006. Retrieved from http://www.oecd.org/education/skills-beyond-school/36278531.pdf

Seber, G. A., \& Lee, A. J. (2012). Linear Regression Analysis (2 ${ }^{\text {nd }}$ ed.). Hoboken, NJ: John Wiley \& Sons, Inc.

Stimson, R. J., Stough, R. R., \& Roberts, B. H. (2006). Regional Economic Development: Analysis and Planning Strategy ( $2^{\text {nd }}$ ed.). Berlin-Heidelberg: Springer-Verlag GmbH.

Lee, S. Y., Florida, R., \& Gates, G. (2010). Innovation, Human Capital, and Creativity. International Review of Public Administration 14(3), 13-24. https://doi.org/10.1080/12294659.2010.10805158

Lutz, W., Scherbov, S., \& Volkov, A. (2002). Demographic Trends and Patterns in the Soviet Union before 1991. London: Routledge.

UNESCO. (2012). International Standard Classification of Education - ISCED 2011. Retrieved from http://www.uis.unesco.org/Education/Documents/isced-2011-en.pdf

World Economic Forum. (2015). The Human Capital Report 2015. Retrieved from http://www3.weforum.org/docs/WEF_Human_Capital_Report_2015.pdf

\section{AUTHORS' SHORT BIOGRAPHIES}

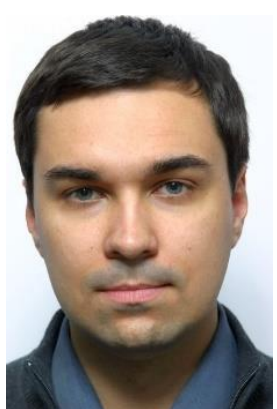

Vladimirs Rojenko is currently a PhD candidate in the field of management with the University of Latvia. He received the Master degree in Management and Leadership from the University of Latvia in 2013 and the Bachelor degree in Management in 2011.

$\mathrm{He}$ is currently an External Lecturer with the Faculty of Economics and Management of the University of Latvia in Riga, Latvia. He previously has been a Chief Procurement Officer and an Internal Auditor with the University of Latvia and a Manager in private and public sectors. His research field is employee creativity management in private enterprises.

E-mail: vladimirs.rojenko@lu.lv 


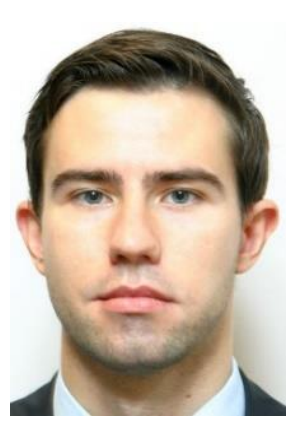

Aleksandrs Dahs is currently a PhD candidate in the field of socio-economic demography with the University of Latvia. He received the Master degree in European Studies from the University of Latvia in 2013 and the Bachelor degree in Management Science in 2011.

He is currently a Researcher and Lecturer with the Faculty of Economics and Management of the University of Latvia in Riga, Latvia. He previously has been a Senior Desk Officer with the Ministry of Interior of the Republic of Latvia and a Senior Manager with a private industrial enterprise.

$\mathrm{He}$ is a full member of Latvian Geographical Society, Latvian Association of Econometrics and the European Association for Population Studies.

E-mail: aleksandrs.dahs@lu.lv 